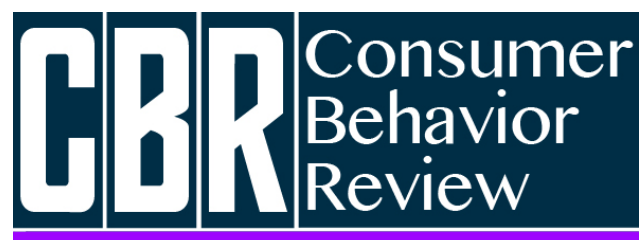

Revista Comportamento do Consumidor
Moura, L. P. A., \& Araujo, F. F. (2020). Influência dos pares nas práticas de consumo: análise do grupo de referência no Filme Meninas Malvadas. Consumer Behavior Review, 4(1), 1-18.
ISSN: 2526-7884

Editor: Prof. Dr. Marconi Freitas da Costa Journal's e-mail: cbr@ufpe.br
Evaluation: Double blind review

Received: 20 de julho de 2019

Accepted: 27 de janeiro de 2020

\title{
INFLUÊNCIA DOS PARES NAS PRÁTICAS DE CONSUMO: ANÁLISE DO GRUPO DE REFERÊNCIA NO FILME MENINAS MALVADAS
}

\author{
Influence of Peers on Consumer Practices: Analysis of the Reference Group in the film Mean Girls
}

Larissa Pereira Alexandria de Moura ${ }^{1}$

ORCID: https://orcid.org/0000-0002-8979-3427

E-mail: larissaalexandria@id.uff.br

Fábio Francisco de Araujo $^{2}$

ORCID: https://orcid.org/0000-0002-5581-5640

E-mail: fabiofdearaujo@gmail.com

\author{
${ }^{1}$ Departamento de Administração, Universidade Federal Fluminense, Macaé, Brasil \\ ${ }^{2}$ Instituto de Nutrição Josué de Castro, Universidade Federal do Rio de Janeiro, Rio de Janeiro, Brasil
}

\begin{abstract}
Resumo
0 presente artigo tem por objetivo analisar como a influência dos grupos de referência e o poder social que estes exercem, impactam as práticas de consumo e a adequação da identidade dos indivíduos, a partir do filme Meninas Malvadas. Este artigo adotou o método de análise qualitativo de imagens em movimento, realizando-se uma descrição do filme nas sequências (unidades narrativas) e, por fim, uma análise de conteúdo. A partir dessa análise, foi possível demarcar as categorias potenciais referente ao poder social dos personagens estudados como poder coercitivo, poder de recompensa, poder de legítima reciprocidade e poder de
\end{abstract}

\begin{abstract}
The purpose of this article is to analyze how the influence of the reference groups and the social power affects the consumer behavior; this analysis is made from the movie Mean Girls. The article adopted the method of qualitative analysis of moving images, making a description of the film in the sequences (narrative units) and, finally, performing a content analysis. From this analysis, it was possible to demarcate the potential categories referring to the social power of the characters studied as coercive power, reward power, power of legitimate reciprocity and power of information. The results indicate to the discussion of social power as a useful tool to
\end{abstract}


informação. Os resultados apontam para a discussão do poder social como um instrumento útil aos membros de uma sociedade, reverberando em práticas e ideologias de consumo que contribuem para que os efeitos de um ambiente segregado de alta competitividade sejam mitigados e, assim, tende a promover o equilíbrio entre quem são e a influência dos grupos que pertencem.

Palavras-chave: Comportamento do Consumidor; Grupos de Referência; Poder Social; Identidade Social. the members of a society, in order to make individuals aware of the mitigation of the effects of a segregated environment of high competitiveness and thus to strike the balance between who they are and the influence of the groups they belong.

Keywords: Consumer Behavior; Reference Groups; Social Power; Social Identity.

Esta obra está licenciada com uma Licença Creative Commons Atribuição 4.0 Internacional.

\section{INTRODUÇÃO}

Os estudos relacionados ao comportamento do consumidor têm avançado bastante nos últimos anos, ocupando hoje posição de importância nas ciências sociais (Campbell, 1991). Junto ao interesse pelo tema veio uma considerável troca interdisciplinar, que estabeleceu conexão entre pesquisadores de diversas áreas (MacInnes \& Folkes, 2010), proporcionando o aprofundamento da disciplina sob diferentes vertentes e encaminhamentos teóricos (Araujo \& Rocha, 2016).

Neste contexto, Belk (1988) deu aporte para o desenvolvimento do tema, ressaltando que o consumo ajuda a definir a identidade do indivíduo, criando o conceito de eu-estendido (extended self), trazendo assim nova perspectiva para o comportamento do consumidor. Para o autor, as pessoas buscam também satisfazer necessidades sociais por meio do consumo e se valem de alguns objetos para identificar-se a si mesmo, tornando-os especiais. Indo ao encontro deste pensamento, Solomon (2016) sublinha que os grupos de referência são capazes de influenciar de diversas maneiras as decisões de compra dos indivíduos, os quais estão sempre em busca de ascensão social. Segundo o autor, os grupos de referência são persuasivos devido ao poder potencial que eles têm sobre as pessoas, tornando-as desindividualizadas, ou seja, os membros do grupo com frequência fazem coisas que não fariam como indivíduos porque suas identidades se fundem com o grupo. Além disso, conforme mencionam Camelo, Thomé e Junqueira (2018), os valores socialmente compartilhados influenciam significativamente as escolhas dos consumidores.

Vale também mencionar o processo de construção de identidade coletiva que, para Jenkins (2005), se atribui à interação com o outro. Para o autor, a identificação é o mecanismo que as pessoas utilizam para se diferenciar umas das outras, tanto de forma individual quanto coletiva. Neste último, a identificação se baseia nas semelhanças entre os indivíduos que compõem o grupo, de forma a se observar o grupo como sendo coeso. Bauman (2005) acrescenta que este processo é o equivalente à pergunta "Quem sou eu?".

A escolha da análise do filme Meninas Malvadas (Mean Girls, 2004), se deve ao fato de a produção cinematográfica estar presente nos âmbitos social e cultural, servindo de reflexo para a compreensão de fenômenos reais (Hirschman \& Stern, 1994). Apesar de os textos culturais, como filmes, comerciais, anúncios, seriados e telenovelas, serem pouco utilizados no campo da pesquisa em comportamento do consumidor, são importantes veículos da cultura, dos valores e das perspectivas vigentes na sociedade (Suarez, Motta \& Barros 2009). Loizos (2002) comenta que os textos culturais podem servir como um rico material de pesquisa, pois o audiovisual e a mídia desempenham uma significativa função política, social e econômica.

Tendo em vista essas considerações, este artigo busca responder a seguinte questão: de que maneira o texto cultural estudado ajuda a compreender a influência e o poder social dos grupos de referência no comportamento de consumo dos indivíduos? 
0 artigo investiga como a influência dos grupos de referência e o poder social que estes exercem, influenciam nas práticas de consumo e na adequação da identidade individual das pessoas à luz do filme Meninas Malvadas. 0 estudo tem por objeto compreender como estes utilizam do poder social para persuadir o alvo da influência. Sendo assim, o trabalho se limita a estudar a produção cultural já citada, objetivando a influência do grupo de referência.

\section{FUNDAMENTAÇÃO TEÓRICA \\ Cultura e o Comportamento do Consumidor}

A concepção de que pessoas consomem para satisfazer necessidades físicas e biológicas foi durante muito tempo a explicação mais propagada sobre a motivação do consumo (Sahlins, 1976), contudo, com o processo de globalização, esse cenário começou a mudar. Segundo McCracken (1988), foi a partir do século XX que se percebe que a sociedade passa a absorver a cultura também por meio do consumo, criando assim um vínculo inédito entre ambos.

Barbosa e Campbell (2006) destacam a impossibilidade de separar consumo de cultura, uma vez que todo o processo, seja ele de seleção, escolha, aquisição, uso ou ainda descarte de um objeto só ocorre e faz sentido dentro de um sistema cultural. Conforme o entendimento de Slater (2002), todo consumo é, por consequência, cultural, pois abrange valores e significados compartilhados socialmente. "Tudo que consumimos possui um significado específico, através do qual reproduzimos nosso sistema de relações sociais" (Slater, 2002, p.17).

Solomon (2016) complementa a ideia ao dizer que a cultura pode ser considerada a personalidade de uma sociedade, a qual inclui seus valores, ética e objetos materiais produzidos por seus membros. Para o autor, a cultura é a acumulação de significados e tradições compartilhadas entre os membros de uma sociedade, e que essa está continuamente evoluindo, mesclando velhas e novas ideias.

0 termo "significados" é um conjunto de percepções que permitem ao homem criar categorias de experiências que se encaixam na sua maneira de ver a realidade, permeando-as de sentido (Kleine III \& Kernan, 1988). Dessa forma, não são pertinentes aos objetos, mas sim por quem os interpreta, sendo os objetos adquiridos por diferentes razões e dotados de significados individuais difíceis de serem transferidos (Ahuvia, 2005). Nesse sentido, o comportamento do consumidor perante a algum produto pode ser definido pelos significados atribuídos a ele e não somente por seus atributos utilitários (Araujo, Turano \& Vieira, 2019).

Para Giddens (2002), o consumo é parte de um estilo de vida, composto por escolhas realizadas por um certo ator. No entanto, o processo de construção de um estilo de vida é diretamente influenciado pelo contexto social, conforme observa o autor. Camelo, Thomé e Junqueira (2018) sublinham as influências nas escolhas dos consumidores são resultados dos valores socialmente compartilhados, que produzem e reproduzem comportamentos, ainda que este fenômeno não ocorra de modo consciente. Segundo Giddens (2002), as pessoas estão em busca de sua própria segurança ontológica, ao mesmo modo em que as alterações e inconstância de suas próprias escolhas confrontadas com a de outros, pode gerar processos de diferenciação e exclusão.

\section{A influência do consumo para a construção da identidade}

Alguns autores, como Hall (2005), por exemplo, acreditam que os abalos provocados pelas mudanças ocorridas na passagem para a pós-modernidade, geraram o deslocamento e fragmentação da identidade, dando oportunidade para o surgimento de novas identidades, que podem ser multifacetadas e, muitas vezes, antagônicas. Bauman (2005) discute a questão da identidade e articula com as características da sociedade que as pessoas estão inseridas, referindo-se à pós-modernidade como composta por condições "fluidas", uma vez que o indivíduo almeja conseguir alguma segurança por meio da identidade. A identidade é, portanto, estruturada por um processo contínuo, de "estar" e "se tornar", não sendo pré-determinada, nem estática no tempo (Jenkins, 2005). Holt (2002), acrescenta essa ideia ressaltando que o consumo pode ser entendido como instrumento de construção, manutenção e modificação da identidade dos indivíduos (HOLT, 2002). 
Segundo Belk (1988), o consumo integra a identidade dos indivíduos, no qual alguns bens possuídos podem ter valor especial, de tal maneira que seus donos os considerem como uma extensão de si. Para Belk (1988), os consumidores se valem do consumo para estender, ampliar e fortificar seu senso de self. 0 autor explica que o self constitui-se naquilo que é avaliado como parte do "eu", já o "self estendido" ou "eu-estendido", estaria associado com tudo aquilo que o indivíduo julga como seu, ou seja, o "eu" e o "meu".

A extensão do self é uma forma de se descobrir ou de saber quem uma pessoa realmente é, não se restringindo apenas aos objetos meramente físicos (Dodson, 1996; Ahuvia, 2005), mas também ao próprio corpo, às coleções (Belk, 1988), a artefatos (Mehta \& Belk, 1991), ao trabalho (Tian \& Belk, 2005), a animais (Sanders, 1990) e a grupos sociais (Smith \& Henry, 1996). Segundo os resultados de pesquisa de Faria et al. (2019), tal fenômeno também é observado pelos pesquisadores do tema no Brasil, que, segundo os autores, valem-se da relação pessoa-objeto, principalmente o conceito do self estendido proposto por Belk, para estabelecer sua narrativa investigativa sobre o assunto. Nessa perspectiva, o indivíduo seria socialmente percebido como a soma de tudo aquilo que este pode chamar de seu: casa, cidade, lugares frequentados, amigos, animais, roupas, dentre outros elementos. Nesse sentido, assume-se que as posses contribuem significativamente para a constituição e reflexão das identidades, e que identidade e entendimento de self são sinônimos, pois determinam subjetivamente como uma pessoa percebe quem ela própria é (Belk, 1988).

\section{A influência do grupo de referência}

Grupo de referência é definido por Bearden e Etzel (1982), como um grupo de pessoas que influenciam significativamente o comportamento de um indivíduo. Engel (2005), acrescenta afirmando que esses grupos influenciam na conduta dos indivíduos em termos de pensamento, sentimentos e padrões de comportamento. Para Sheth, Mittal e Newman (2001, p.165), os grupos de referência são "pessoas, grupos e instituições a que os indivíduos recorrem para uma orientação de seu próprio comportamento e valores, e dos quais esses indivíduos buscam aprovação". Portanto, um grupo de referência é qualquer indivíduo ou grupo que sirva como um parâmetro de comparação para formação de valores, crenças, atitudes, entre outros que guiem o comportamento (Araujo \& Rocha, 2019; Breheny \& Stephens, 2017; Dias, 2009; Scott \& Harmon, 2016; Vouga, 2017).

Solomon (2016) defende a ideia de que todos os indivíduos fazem parte de algum grupo e seguem as pistas de como se comportar observando as ações dos outros a sua volta, tentando agradar os membros do grupo cuja aceitação lhes interessa. Para o autor, a necessidade que algumas pessoas têm de "adequar-se" ou de identificar-se com pessoas ou grupos desejáveis é a primeira motivação para muitas de suas atividades e práticas de consumo. Como destacado por Lima, Costa e Felix (2019), o comportamento do indivíduo tende a ser afetado por sentimentos construídos a partir de estímulos externos advindos do contexto social que são capazes gerar culpa ou orgulho diante de uma determinada prática de consumo.

Conforme esclarece Solomon (2016), o marketing apela para os grupos de referência focando em figuras bastante visíveis e admiradas, como atletas ou artistas bem conhecidos, de maneira que os produtos e as marcas que estes usam ou endossam também adquiram uma qualidade a que os consumidores aspiram. Tais iniciativas persuasivas para comercializar produtos e marcas são a confirmação da convicção de que os grupos de referência revelam comportamentos e estilos de vida às pessoas, influenciam o desenvolvimento do autoconceito, colaboram para a formação de valores e atitudes, e usam a persuasão para que as normas do grupo sejam aceitas (Bearden \& Etzel, 1982).

As implicações dos grupos de referência são significativas e relevantes para as estratégias de marketing, pois têm influência direta e imediata sobre as respostas cognitivas, afetivas e comportamentais dos consumidores (Peter \& Olson, 2009). Um grupo de referência é somente uma das fontes de influência dos consumidores. Assim, também leva-se em consideração outras situações que corroboram o argumento de que o grupo de referência exerce influência nas decisões de compra do consumidor, como o desejo de aceitação social, pouca experiência com a situação de compra, se a compra deve ser consumida em público ou em particular, se é luxo ou necessidade, a falta de confiança em propagandas, entre outros, conforme vem sendo analisado em diferentes pesquisas ao longo dos 
últimos anos (Bastos, Costa \& Vasconcelos, 2017; Bearden \& Etzel, 1982; Bearden, Netemeyer \& Teel, 1989; Blackwell, Miniard \& Engel, 2005; Park \& Lessing, 1977; Sheth, Mittal \& Newman, 2001; Solomon, 2016).

Os grupos de referência são tão persuasivos, segundo Solomon (2016), devido ao poder social que eles têm sobre as pessoas. Poder e influência são temas que têm suscitado reflexão durante anos, de acordo com Somech e Drach-Zahavy (2002), a noção de poder e de influência têm sido o ponto de atenção de pesquisadores por várias décadas. 0 fenômeno da influência social é um dos fenômenos que mais comumente ocorrem no relacionamento interpessoal, pois constantemente os indivíduos estão tentando influenciar outras pessoas e sendo por elas influenciados (Rodrigues, Assmar \& Jablonski, 2003).

A diferença entre poder e influência, com base nos estudos feitos por French e Raven (1959), é que poder social é a habilidade potencial de um indivíduo ou agente de influenciar outro individuo ou alvo, já a influência é a força que o ator exerce sobre o alvo para induzir mudança nesse alvo. Quando se presume que o poder é potencial e influência pressupõe ação, admite-se que, ao abordar o tema influência, é necessário discutir as formas pelas quais os indivíduos efetivamente a exercem, ou seja, o alvo, o motivo, o dispositivo preparatório, a estratégia utilizada e a base de poder escolhida.

Segundo Raven (1990), o modelo poder/interação de influência interpessoal descreve o agente influenciador como um ator racional, que analisa custos e benefícios das bases de poder acessíveis antes de fazer uso de uma delas para influenciar seu alvo. Ainda segundo o autor, o agente pode, além de escolher uma estratégia de influência, resolver que alguns cuidados são relevantes antes da tentativa de exercício de poder.

\section{MÉTODO DE PESQUISA}

A perspectiva do estudo se insere dentro de um paradigma qualitativo de teor interpretativo (Minayo, 1992), tratando-se de um estudo descritivo que investiga um fenômeno social contemplando a análise de imagens em movimento, conforme os estudos de Coutinho (2005), Rose (2002) e Cordeiro (1996). Os conceitos-imagem existentes no filme fornecem soluções morais, lógicas, epistémicas, abertas e problemáticas para as questões referentes ao comportamento do consumidor (Cabrera, 2006).

A indústria cinematográfica é um mercado exigente e promissor para diferentes áreas do saber, que tem forte influência sobre os costumes, os hábitos, a moral e o consumo das pessoas (Holbrook, 1999). Apesar de não ser uma novidade nas ciências humanas, a utilização de textos culturais como objeto de estudo ainda é um campo pouco explorado em pesquisas no Brasil (Suarez, Motta \& Barros, 2009). Porém, conforme Araujo e Chauvel (2014), observa-se um crescente aproveitamento do recurso de produções culturais no ambiente acadêmico de forma didática, por abordarem questões socialmente relevantes da história, da política e da cultura.

A análise fílmica estabelece um procedimento esquemático que propõe conectar o cinema com outras áreas da vida ou campos do conhecimento, fomentando sua capacidade de diálogo com outras áreas (Andrew, 2002). Segundo Araujo e Chauvel (2012), esse diálogo e articulação com outras áreas desperta maior possibilidade de compreensão de fenômenos sociais a partir da experiência desenvolvida e vivida pelos personagens. Nesse sentido, os filmes podem funcionar como um forte veículo das representações sociais, uma vez que muitos roteiros se baseiam na realidade ao estimular a reflexão em torno do sentido que o homem atribui à sua vida (Wood Jr., 1997), trazendo desde informações críticas e históricas sobre a sociedade e a humanidade, até entretenimento, pois são enraizadas em realidades, tradições e por "redes de significados" (Geertz, 1973, p.5).

A análise da produção audiovisual Meninas Malvadas (Mean Girls, 2004) está ancorada na leitura e na interpretação integrada de texto (Thompson, 1997; Wearing, 1993), imagem, som (Rose, 2002) e de características não-verbais (Birdwhistell, 1970). As características não-verbais consideradas neste estudo foram extraídas de percepções das cenas não faladas, mas que traziam significados importantes ao fenômeno de análise, entre as quais, pode-se destacar: ambientação e composição do lugar, expressões faciais, olhares, posturas corporais, até mesmo distância corporal entre os personagens. Conforme proposto por Rose (2002), a primeira etapa para a análise das 
imagens é a seleção das cenas, que seguem um referencial de codificação. Em sequência, foi feito a transcrição de um conjunto de dados extraídos das narrativas, dos diálogos e das imagens, visando-se obter uma padronização da análise. Junto à análise das imagens foram adicionados aspectos relevantes das cenas, tais como as cores e os tipos de roupas dos personagens, o cenário e os elementos que compõem a cena (Silverman, 1993; Kidder \& Judge, 1986).

Optou-se por realizar um detalhamento do filme em sequências, conforme sugerido por Passarelli (2004). Essas sequências em (S) foram numeradas, para ajudar no processo de observação do texto cultural, já as informações visuais e verbais utilizadas, foram descritas em forma de texto, conforme orientado por Rose (2002).

0 estudo se propôs a obter algumas percepções de como os grupos de referência moldam as preferências de consumo daqueles que participam do grupo. A partir da análise dos personagens, as cenas foram sendo selecionadas, considerando situações do texto cultural escolhido em que relacionava experiência de consumo à influência do grupo de referência. Para essa etapa, o Quadro 1 elenca a descrição do filme cronologicamente nas sequências (S). Tratam-se de unidades narrativas, determinadas por mudanças de plano, de cenário e/ou entrada de novos personagens:

\begin{tabular}{|c|c|}
\hline$S$ & Texto \\
\hline 1 & $\begin{array}{l}\text { Cady não encontra lugar para sentar no refeitório da escola, pois todos os alunos estão divididos em grupos e } \\
\text { não permitem a inserção dela no meio deles. Cady resolve então comer sozinha no banheiro. }\end{array}$ \\
\hline 2 & $\begin{array}{l}\text { Janis e Damian descrevem as "poderosas" da escola para Cady, dizendo a particularidade de cada uma. Damian } \\
\text { refere-se a Regina George como a abelha-rainha das poderosas, sendo Karen Smith e Gretchen Wieners as } \\
\text { operárias. }\end{array}$ \\
\hline 3 & $\begin{array}{l}\text { Janis se pergunta como poderia descrever Regina George, tentando, aparentemente, encontrar as palavras certas. } \\
\text { Na cena seguinte, vários alunos da escola North Shore expressam o seu pensamento e percepção sobre Regina } \\
\text { George, ficando nítido que todos a conhecem e a admiram. Portanto, independente do grupo que participam, os } \\
\text { alunos conhecem a vida da Regina, suas práticas de consumo, bem como seus gostos e hábitos. }\end{array}$ \\
\hline 4 & $\begin{array}{l}\text { Janis mapeia toda a escola para Cady, ressaltando a importância do lugar onde a nova aluna irá se sentar no } \\
\text { refeitório, afinal, todos os alunos estarão no local. } \\
\text { Calouros, playboys, mauricinhos, atletas juniores, nerds asiáticos, asiáticos legais, atletas, gatas negras sebosas, } \\
\text { meninas que comem demais, meninas que não comem nada, desesperados pela fama, sequelados, roqueiros } \\
\text { sexualmente ativos, as pessoas mais legais do mundo (Janis e Damian) e as piores (Regina, Gretchen e Karen), } \\
\text { são os grupos da escola indicados por Janis, de acordo com a compatibilidade de pensamentos e características. }\end{array}$ \\
\hline 5 & $\begin{array}{l}\text { Cady é convidada por Regina George a almoçar durante a semana com as poderosas. Apesar de Cady não } \\
\text { entender o motivo, Janis implora para que a amiga aceite o convite e passe a contar para ela tudo que as } \\
\text { poderosas falam e fazem. }\end{array}$ \\
\hline 6 & $\begin{array}{l}\text { Cady sentia-se em outro mundo almoçando com as poderosas, no Mundo das Garotas, o qual haviam muitas } \\
\text { regras a se cumprir. } \\
\text { Gretchen: Não se usa pulôver dois dias seguidos e só pode usar rabo de cavalo uma vez por semana. Mas você } \\
\text { escolheu hoje. E nós só usamos jeans ou moletons na sexta-feira. Se você quebrar alguma regra, não poderá almoçar } \\
\text { conosco. Se eu estivesse vestindo jeans hoje, estaria sentada com os metidos a artista. Votamos antes de convidar } \\
\text { alguém para almoçar em consideração ao grupo. Você não compraria uma saia sem pedir a opinião das amigas! O } \\
\text { mesmo se aplica aos garotos. Pode achar que gosta de alguém, mas está errada. }\end{array}$ \\
\hline 7 & $\begin{array}{l}\text { Por ser muito boa em matemática, Cady é convidada pelo capitão dos Matletas para participar da equipe. Ele } \\
\text { explica que os Matletas participam de competições de matemática e que conseguiriam dobrar o patrocínio com a } \\
\text { presença de garotas na equipe. Cady promete pensar, porém desconsidera o convite quando as poderosas dizem } \\
\text { ser "suicídio social" participar dos Matletas. } \\
\text { Mais tarde, ao contar também para Janis e Damian sobre o convite, Cady tem a mesma recepção: suicídio social. }\end{array}$ \\
\hline 8 & $\begin{array}{l}\text { Ao chegar próxima do chafariz do shopping, Cady lembra da realidade vivida na África, e compara mentalmente } \\
\text { com a fonte onde os animais no cio se reuniam. }\end{array}$ \\
\hline 9 & $\begin{array}{l}\text { Para Cady os únicos defeitos que uma pessoa poderia ter seria ser gordo ou magro. Porém, notou que estava } \\
\text { errada ao ver Regina, Gretchen e Karen colocando defeitos diversos em si mesmas. } \\
\text { Ao perceberem o silêncio de Cady, as meninas olham para ela esperando que a mesma diga algo que a incomode } \\
\text { em seu próprio corpo. Cady, sem saber o que dizer, apenas diz que tem mau hálito de manhã. }\end{array}$ \\
\hline 10 & $\begin{array}{l}\text { A mãe de Regina tenta ser descolada, utilizando gírias atuais e querendo participar das conversas. Ao sair, diz } \\
\text { que as meninas a mantém jovem e que as ama muito. }\end{array}$ \\
\hline 11 & $\begin{array}{l}\text { As poderosas encontram o "Burn Book". Um livro antigo feito por elas mesmas, com a foto de outros } \\
\text { frequentadores da escola e comentário. Todos os comentários são ofensivos, representando o pensamento delas } \\
\text { sobre essas pessoas. }\end{array}$ \\
\hline 12 & $\begin{array}{l}\text { Cady finge não estar entendendo a matéria de matemática apenas para ter motivos para falar com Aaron, rapaz } \\
\text { pelo qual se apaixonou desde o primeiro dia de aula, porém, por ser ex namorado de Regina, Cady estava }\end{array}$ \\
\hline
\end{tabular}




\begin{tabular}{|c|c|}
\hline & proibida de ter algum tipo de relacionamento com o rapaz. \\
\hline 13 & $\begin{array}{l}\text { Cady é convidada por Aaron para ir à uma festa de Halloween, no entanto suas referências de festa de Halloween } \\
\text { são diferentes das dos estudantes de Noth Shore, que se aproveitam da data para usarem roupas sexys sem } \\
\text { serem julgados. Cady, sem saber dessa informação, vai à festa vestida de noiva zumbi e assusta a todos. }\end{array}$ \\
\hline 14 & $\begin{array}{l}\text { Regina promete ajudar Cady a conquistar o Aaron, porém ao conversar com ele, inventa que Cady irá fazer um } \\
\text { vodu africano para que ele se apaixone por ela, dentre outras mentiras. Aaron fica assustado com as informações } \\
\text { passadas por Regina que, por sua vez, se aproveita da situação e o beija na frente de Cady. }\end{array}$ \\
\hline 15 & Regina exibe Aaron para a Cady que, mais uma vez, imagina como seria se estivessem no mundo animal. \\
\hline 16 & $\begin{array}{l}\text { Janis, na tentativa de prejudicar a imagem de Regina, corta a blusa da rival na região dos seios. Porém, assim que } \\
\text { Regina coloca a blusa, não se incomoda com o fato de seu sutiã estar aparecendo e sai do vestiário normalmente. } \\
\text { Assim que as outras estudantes veem, resolvem imitar, cortando também suas blusas para deixar amostra o } \\
\text { sutiã. }\end{array}$ \\
\hline 17 & $\begin{array}{l}\text { Cady, envia bengalas de açúcar de Natal com mensagem de agradecimento pela amizade para si mesma e para a } \\
\text { Karen, fingindo ser Regina George, sem enviar, estrategicamente, para a Gretchen, que fica extremamente } \\
\text { ressentida e finda a contar alguns segredos da Regina para Cady. }\end{array}$ \\
\hline 18 & $\begin{array}{l}\text { Regina manda Gretchen trocar de lugar com Cady na hora da dança de Natal. Isso a abala mais ainda, fazendo-a } \\
\text { pensar que Regina está chateada com ela. }\end{array}$ \\
\hline 19 & $\begin{array}{l}\text { Gretchen conta à Cady que não pode usar brincos de argola e que, inclusive, teve que fingir que não havia } \\
\text { gostado das argolas caríssimas de ouro branco que seus pais lhe deram, pois, segundo Regina, brincos de argola } \\
\text { são exclusividade dela. }\end{array}$ \\
\hline 20 & $\begin{array}{l}\text { Cady oferece à Regina barras de nutrição que sua mãe costumava dar para crianças desnutridas na África. Ela faz } \\
\text { isso a fim de colocar em ação o plano de destruir o corpo bonito de Regina. Regina, por sua vez, apesar de não } \\
\text { entender o que estava escrito na descrição dos ingredientes, confia em Cady e passa a comer as barras. }\end{array}$ \\
\hline 21 & $\begin{array}{l}\text { Cady relata como é andar com Regina e ser uma poderosa: } \\
\text { Cady: Era estranho andar com Regina, pois eu a odiava, mas ao mesmo tempo queria que ela gostasse de mim. } O \\
\text { mesmo acontecia com Gretchen. Quanto mais Regina era cruel, mais ela tentava agradá-la. Ela sabia que era } \\
\text { melhor ser poderosa do que não ser. Ser uma poderosa era como ser famosa. Todo mundo prestava atenção em nós, } \\
\text { todo mundo sabia das fofocas. }\end{array}$ \\
\hline 22 & $\begin{array}{l}\text { Várias pessoas aparecem na cena falando o que sabem de Cady e das poderosas. Uma das estudantes diz ter visto } \\
\text { Cady usando calça camuflada, por isso então resolveu comprar uma também. }\end{array}$ \\
\hline 23 & $\begin{array}{l}\text { De frente para o espelho, Cady se vê obcecada, querendo falar sobre Regina George o tempo todo. Na cena é } \\
\text { possível perceber que Cady está mais vaidosa, com os cabelos soltos, de maquiagem e com roupas mais justas, o } \\
\text { que retrata a influência das poderosas no comportamento de consumo de Cady. }\end{array}$ \\
\hline 24 & $\begin{array}{l}\text { Regina havia reservado no início do ano um vestido para o baile, porém, como uma boa poderosa, precisava da } \\
\text { opinião das amigas antes de comprar. }\end{array}$ \\
\hline 25 & $\begin{array}{l}\text { Ao conversar com Janis e Damian, pode-se perceber que Cady adquirira os mesmos trejeitos de Regina. Inclusive, } \\
\text { Aaron, em uma das cenas seguintes, ressalta de forma negativa a semelhança de Cady com Regina no que diz } \\
\text { respeito ao jeito das duas personagens. }\end{array}$ \\
\hline 26 & $\begin{array}{l}\text { Karen e Gretchen chegam ao refeitório dispostas a repreender Regina por não estar de acordo com as regras de } \\
\text { vestimenta impostas pelo grupo. }\end{array}$ \\
\hline 27 & $\begin{array}{l}\text { Gretchen e Karen passaram a seguir Cady durante o resto do dia. "Será que eu era a nova abelha-rainha?", se } \\
\text { perguntou Cady. }\end{array}$ \\
\hline 28 & $\begin{array}{l}\text { Durante uma festa na casa de Cady, Aaron entra no quarto da jovem e encontra uma foto dela criança em cima de } \\
\text { um elefante. O quarto de Cady é rodeado de fotos e objetos que remetem a África, lugar onde viveu da infância à } \\
\text { adolescência. Esses objetos expressam a identidade de Cady. }\end{array}$ \\
\hline 29 & $\begin{array}{l}\text { Janis descobre que Cady não foi à sua exposição para dar uma festa, para a qual nem ela e nem Damian haviam } \\
\text { sido convidados. A mudança de comportamento de Cady devido a influência do atual meio de convívio } \\
\text { desencadeou uma discusano entre as duas personagens. }\end{array}$ \\
\hline 30 & $\begin{array}{l}\text { Após Regina George espalhar pelo colégio cópias das páginas do "Burn Book", nota-se a demarcação da } \\
\text { segmentação por grupos existente na escola. Cada integrante tinha uma divergência em particular com outros do } \\
\text { mesmo grupo, portanto, a professora de matemática, Sra Norbur, faz com que estes se exponham uns para os } \\
\text { outros, relevando seus respectivos problemas e aflições. }\end{array}$ \\
\hline 31 & $\begin{array}{l}\text { A mãe de Cady encontra seus vasos tribais dentro do armário da cozinha, guardados por Cady no dia da festa. Os } \\
\text { vasos têm grande valor simbólico para mãe de Cady, dotados de significados e lembranças. Já Cady, ao ser } \\
\text { contestada pela mãe sobre a importância dos objetos, demonstra não ter nenhum vínculo com estes. A partir } \\
\text { desta afirmação a mãe de Cady indaga "Quem é você??". }\end{array}$ \\
\hline 32 & $\begin{array}{l}\text { Após um acidente com Regina George, no qual um ônibus a atropela, Cady se encontra mais uma vez sem espaço } \\
\text { nos grupos da escola e resolve passar o intervalo sozinha no banheiro, como da primeira vez. }\end{array}$ \\
\hline 33 & $\begin{array}{l}\text { Como forma de se desculpar com a Sra. Norbury, Cady participa do campeonato estadual de matemática como } \\
\text { integrante dos Matletas. Ao se dirigir à mesa de respostas para a pergunta de "morte súbita", Cady avalia a } \\
\text { adversária e faz uma autocrítica, indo contra as suas recentes atitudes: } \\
\text { Cady: A Srta. Krafft precisava tirar as sobrancelhas urgentemente. O vestido parecia ter sido escolhido por um } \\
\text { padre cego. E havia batom barato nos seus dentes. Mas zombar da Caroline Krafft não a impediria de me vencer. }\end{array}$ \\
\hline
\end{tabular}




\begin{tabular}{|c|l|}
\hline 34 & $\begin{array}{l}\text { Chamar alguém de gorda não nos torna mais magra. Chamar alguém de estúpida não nos faz mais espertas. } \\
\text { Arruinar a vida da Regina não me fez mais feliz. Na vida, temos que resolver os nossos próprios problemas. }\end{array}$ \\
\hline $\begin{array}{l}\text { As poderosas se separaram. Regina passou a canalizar toda sua raiva nos esportes no qual as atletas não tinham } \\
\text { medo dela. Karen começou a trabalhar com previsão do tempo. Gretchen achou um novo grupo e uma nova } \\
\text { abelha rainha para servir. }\end{array}$ \\
\hline
\end{tabular}

Fonte: Elaboração dos autores.

Quadro 1. Descrição do Filme Meninas Malvadas em Sequências (unidades narrativas)

Para o tratamento dos dados, Rose (2002) sugere que no método de análise de imagens em movimento seja realizada uma análise a partir da sistematização dos dados identificados e já codificados, produzindo a construção social da realidade por meio de descrição sistemática dos eventos e/ou por meio de construção de categorias identificadas pela frequência de determinado aspectos que se repete nas cenas e que guardam relação com o fenômeno analisado. Hirschman, Scott e Wells (1998), que realizaram um estudo no qual propõem um modelo para análise de produções culturais, também sublinham que a construção de categorias de análise é uma forma adequada de interpretar os textos culturais.

Assim, a análise sistemática dos foi elaborada considerando os aspectos da cultura de consumo, o comportamento, os dilemas identitários dos personagens e os impactos a influência do grupo de referência, que foram reproduzidos nos diferentes diálogos e nas sequencias relevantes identificados ao longo do filme, os quais foram reunidos e expressos no Quadro 1, apresentado nesta seção. 0 desenvolvimento do tratamento analítico dos dados seguiu um processo interpretativo hermenêutico (Thompson, 1997), que permitiu a identificação de um padrão de ideias relativo às bases de poder de influência social e puderam ser explicitadas em seis categorias de análise. As categorias identificadas foram próximas das características de poder e influência social apontadas no estudo de Raven (1992) e, por essa razão, optou-se por articulá-las ao processo interpretativo desta pesquisa. As categorias de análise são detalhadas na seção de análise dos resultados apresentada a seguir.

\section{ANÁLISE DOS RESULTADOS}

A partir do filme Meninas Malvadas, tendo em vista as características dos personagens, os fenômenos culturais observados durante a análise, e os padrões de ideias sobre as bases de poder de influência social identificados na análise dos dados, percebeu-se que o modelo proposto por Raven (1992) seria oportuno para empreender o processo interpretativo do presente estudo. A construção simbólica dos significados presentes nos discursos do texto cultural Meninas Malvadas, assim como ações e comportamentos dos personagens do filme se articulam com relativa harmonia às características trazidas pelo modelo.

Nos próximos subitens desta seção é apresentada a análise do texto cultural do filme Meninas Malvadas. Para essa etapa, Quadro 2 elenca os agentes influenciadores com os seus respectivos alvos de influência, relacionando-os com as motivações para a influência, os dispositivos preparatórios, as bases de poder e táticas de influência.

As seis bases de poder apresentadas são: o poder de recompensa, o poder coercitivo, o poder legítimo, o poder de referência, o poder de especialista e o poder de informação. Para Rodrigues, Assmar e Jablonski (2003), cada uma das seis bases de poder referidas constituem categorias potenciais para a influência social.

\begin{tabular}{|c|c|c|c|c|c|}
\hline $\begin{array}{c}\text { Agente } \\
\text { Influenciador }\end{array}$ & $\begin{array}{c}\text { Alvo da } \\
\text { influência }\end{array}$ & $\begin{array}{c}\text { Motivação } \\
\text { para a } \\
\text { Influência }\end{array}$ & $\begin{array}{c}\text { Dispositivos } \\
\text { preparatórios }\end{array}$ & Bases de Poder & $\begin{array}{c}\text { Táticas de } \\
\text { Influência }\end{array}$ \\
\hline Regina George & $\begin{array}{c}\text { Gretchen } \\
\text { Wieners e } \\
\text { Karen Smith }\end{array}$ & $\begin{array}{c}\text { Exigências do } \\
\text { papel }\end{array}$ & Intimidação & Poder coercitivo & Enérgica \\
\hline Regina George & Cady Heron & Satisfazer & Insinuação & Poder de & Branda \\
\hline
\end{tabular}




\begin{tabular}{|c|c|c|c|c|c|}
\hline & & $\begin{array}{l}\text { necessidades } \\
\text { internas }\end{array}$ & & recompensa & \\
\hline Janis Ian & Cady Heron & $\begin{array}{c}\text { Atingir metas } \\
\text { extrínsecas } \\
\text { (justiça) }\end{array}$ & $\begin{array}{l}\text { Fazer favores } \\
\text { visando à } \\
\text { legitimidade } \\
\text { recíproca }\end{array}$ & $\begin{array}{l}\text { Poder de } \\
\text { legitimidade de } \\
\text { reciprocidade }\end{array}$ & Racional \\
\hline Cady Heron & Regina George & $\begin{array}{l}\text { Desejo de } \\
\text { prejudicar }\end{array}$ & $\begin{array}{l}\text { Estabelecer } \\
\text { poder de } \\
\text { informação }\end{array}$ & $\begin{array}{c}\text { Poder de } \\
\text { informação }\end{array}$ & Racional \\
\hline
\end{tabular}

Fonte: Elaboração dos autores com base em Raven (1992).

Quadro 2. Influência dos pares na perspectiva do filme Meninas Malvadas

\section{O Poder coercitivo}

O filme apresenta seus protagonistas com personalidades bem distintas, mas influenciados de alguma forma por Regina George. A personagem é caracterizada como uma típica patricinha manipuladora e autoritária, que tem como melhores amigas Gretchen Wieners e Karen Smith. Juntas elas formam as "plastics" da escola Noth Shore, na qual Regina George é a líder.

Durante o desenrolar do filme, pode-se identificar o poder coercitivo como forma enérgica de Regina George sob Gretchen e Karen, porém mais intensivamente sob esta última. Regina demonstra, em determinadas cenas do filme, impaciência e intolerância com as amigas, e essas, por sua vez, aceitam esse tratamento de maneira passiva, pois possuem interesse de alcançar a visibilidade social que Regina proporciona a elas.

CADY: Quanto mais Regina era cruel, mais ela (Gretchen) tentava agradá-la. Ela sabia que era melhor ser poderosa do que não ser. Ser uma poderosa era como ser famosa. Todo mundo prestava atenção em nós, todo mundo sabia das fofocas.

Com base na intimidação social, Regina inibi o comportamento de qualquer pessoa que busque chamar mais atenção que ela, uma vez que considera tal postura uma ameaça à sua imagem e à ordem almejada pela estrutura centralizadora que ela impôs na escola. A autoridade de Regina se destaca em relações de poder que se impregnam nas interações que ela mantém tanto com seus colegas quanto com seus familiares, satisfazendo somente suas próprias necessidades e subjugando os interesses dos demais. 0 comportamento manipulador e repressor de Regina se repete em diversas cenas do filme, refletindo sua tentativa de oprimir e coagir para reforçar sua base de poder (Raven, 1992).

Essa conduta remete à tática enérgica de influenciação de que falam Kipnis e Schmidt (1985). Para os autores, as estratégias enérgicas abrangem exigências, elevação da voz e assertividade, podendo ser tanto solicitações diretas e assertivas de obediência quanto solicitações intermediadas e manipulativas, como ameaças e agressões (Somech \& Drach-Zahavy, 2002). Por meio dessas atitudes, Regina espera que suas demandas sejam atendidas por Gretchen e Karen, como pode-se observar na passagem a seguir, transcrita a partir de um diálogo entre Gretchen e Cady:

GRETCHEN: Se você soubesse como ela é cruel. Ela não me deixa usar brincos de argola. Há dois anos, ela me disse que brincos de argola eram exclusividade dela e eu não tinha mais permissão para usar. No Hanukkah meus pais me deram argolas caríssimas de ouro branco e eu tive que fingir que não tinha gostado. Foi tão triste!

A habilidade de Regina de punir as amigas ou impedi-las de obter recompensas desejadas, vai de encontro a teoria de Somech e Drach-Zahavy (2002) sobre o poder coercitivo. Coerentemente com essa visão, French e Raven (1959, p.156) definem poder coercitivo como o poder "baseado na percepção de $\mathrm{P}$ de que $\mathrm{O}$ tem a habilidade para intermediar punições contra ele". Trazendo a teoria para a realidade do texto cultural estudado, sendo "P" Regina George e "O" Gretchen Wieners e Karen Smith, pode-se perceber que o poder coercitivo de Regina sobre Gretchen e Karen origina-se da 
expectativa por parte das meninas de que serão castigadas por Regina se não se conformarem à tentativa de influência. 0 cumprimento das regras de vestimenta estabelecidas pelo grupo é a comprovação de que os participantes temem não poder sentar na mesa das poderosas no refeitório, bem como a líder Regina George.

Por outro lado, o comportamento de Regina com as amigas é motivado pela exigência do papel que a mesma exerce, ou seja, o seu status social, uma vez que almeja conseguir segurança por meio da identidade (Bauman, 2005). Essa preocupação com a imagem pessoal e o zelo pelo poder, faz com que a personagem apresente uma imagem que desperta medo em Gretchen e Karen, utilizando assim dispositivos preparatórios como intimidação para aumentar e enfatizar seu poder de coerção (Raven, 1992). Uma cena que ilustra essa situação pode ser observada a seguir:

REGINA: Gretchen, troque de lado com a Cady.

GRETCHEN: Mas eu sempre danço à sua esquerda.

REGINA: Bom, isso era quando éramos três. Agora, a mais alta dança no meio.

GRETCHEN: Mas vou ter que dançar ao contrário. Sempre fico à esquerda.

REGINA: E agora está ficando irritante. Troque.

\section{O Poder de recompensa}

Cady Heron é uma estudante da North Shore High School que se mudou para Evanston depois de viver seus últimos 12 anos na África. Cady nunca havia frequentado uma escola antes, e isso faz com que Regina George se interesse por ela e a inclua no grupo das "plastics". Cady é como um diamante a ser lapidado para Regina e justamente por isso quer que a nova estudante goste dela, a influenciando, portanto, de forma branda para satisfazer suas necessidades internas de poder, segurança e autoestima.

A tática de influência de maneira branda, segundo Kipnis e Schmidt (1985) pressupõe uma postura do agente influenciador nitidamente agradável e lisonjeira, adulando aqueles que pretendem influenciar. Essa estratégia envolve um meio de influência menos agressivo e mais psicológico, sendo projetada para assegurar a obediência pela própria vontade do alvo (Somech \& Drach-Zahavy, 2002). Essa técnica de influência utilizada por Regina, pode ser sintetizada no diálogo abaixo, relacionada a busca da obediência de uma maneira cortês e amigável, demonstrando simpatia por Cady ao conhecela:

REGINA: Ai meu Deus! Amei sua pulseira, onde conseguiu?

CADY: Minha mãe fez para mim.

REGINA: É adorável.

Com o intuito de aumentar a atração de Cady, Regina se insinua, com elogios bem colocados e agradáveis, retratando o poder de recompensa salientado por French e Raven (1959). Para os autores, o poder de recompensa é definido como o poder cuja base é a habilidade para recompensar. Nesse sentido, a força do poder de recompensa de Regina sobre Cady aumenta de acordo com a magnitude das recompensas que Cady percebe que Regina poder intermediar por ela. Uma cena que ilustra bem esse comportamento pode ser observado a seguir, porém vale ressaltar que o único objetivo de Regina ao recompensar Cady é conseguir benefícios para si própria.

REGINA: Gretchen me contou que você gosta do Aaron Samuels. Faça o que você quiser. Mas só tenho uma coisa a te dizer sobre o Aaron: ele só pensa nos estudos, na mãe e nos amigos.

CADY: E isso é ruim?

REGINA: Mas se você gosta dele, tanto faz. Posso falar com ele se você quiser.

CADY: Sério? Você faria isso? Mas nada que me deixasse sem graça, certo?

REGINA: Não! Acredite em mim. Eu sei exatamente o que fazer. 
A conduta de Regina vai de encontro a discussão de Barry e Shapiro (1992) sobre os efeitos interativos da combinação de táticas de influenciação. De acordo com os autores, existem bases conceituais para a ideia de que comportamentos brandos ou de insinuação, quando adotados com sucesso, promoverão a submissão em situações de influência social. 0 alvo da influência tende a responder favoravelmente à atratividade, à credibilidade, à perícia e à probidade do agente da influência, enquanto as táticas brandas são projetadas para amplificar essas características do agente (Barry \& Shapiro, 1992).

Dessa forma, para Cady o vínculo com as "plastics" era apenas um jogo para prejudicar a vida de Regina George, porém, sem se dar conta, a personagem modifica suas práticas de consumo, seu comportamento, opiniões, hábitos, atitudes, metas, necessidades, valores e todos os outros aspectos do campo psicológico, definidos por French e Raven (1959) como "sistema". A necessidade de Cady de agradar a Regina, cuja aceitação lhe interessa, faz com que a personagem se adeque ao meio, modificando assim suas atividades e práticas de consumo (SOLOMON, 2016). Essa mudança é o efeito da tática de influência que Regina exerce sobre Cady, bem como o feito da base de poder escolhida.

CADY: Fingi ser ruim em matemática para você me ajudar. Mas eu não sou ruim em matemática. Na verdade, eu sou muito boa em matemática. Você é ruim em matemática. Mas acabei tirando nota baixa.

AARON: Espera. Você tirou nota baixa de propósito? Isso é estúpido.

CADY: Não! Não foi de propósito. Eu só queria uma razão para falar com você.

AARON: Por que então não falou comigo?

CADY: Por que eu não podia. Por causa da Regina. Por que você era propriedade dela.

AARON: Propriedade?

CADY: Não! Cala a boca. Não falei propriedade...

AARON: Não diga para eu calar a boca! Sabe de uma coisa? Você é o clone da Regina.

Outra cena que representa a mudança de comportamento de Cady é quando Janis e Damian descobrem que não foram convidados para a festa na casa da amiga. Inicia-se então uma discussão, na qual Janis enfatiza que Cady já foi absolvida pelo poder social de Regina:

CADY: Você sabe que não poderia convidar você. Tenho que fingir ser uma poderosa.

JANIS: Você não está mais fingindo. Você é uma poderosa. Cruel, metida, sebosa! Você achou tudo incrível? Você bebeu bebidas incríveis? Você ouviu músicas incríveis? Ficaram admirando como vocês são "demais"?

\section{O Poder de legítima reciprocidade}

Janis e Damian logo se tornam amigos de Cady Heron, a ensinando algumas coisas básicas sobre o colégio e as pessoas que lá estudam, falando principalmente sobre quem são as "plastics" e o porquê a nova estudante deve evita-las. Porém, quando Cady é convidada para participar do grupo, Janis tenta convence-la a aceitar para que possa se vingar de Regina George.

A motivação de Janis é fazer justiça, não só por si mesma, mas por todas as pessoas que foram diretas ou indiretamente ofendidas por Regina George, assim, com o intuito de atingir metas extrínsecas. A partir da análise de determinadas cenas, pode-se notar a influência de legítima reciprocidade de Janis para com Cady, no intuito de obter interdependência. Segundo Raven (1992), este dispositivo preparatório visa prestar favores ao alvo e enfatizar a dependência do agente em relação à resposta do alvo. De maneira racional, Janis se vale da chateação de Cady (sequência 14) para persuadi-la, fazendo com que a amiga compactue com seu plano de vingança:

JANIS: Olha, ela não vai se safar, "tá" bom? Vamos fazer algo a respeito.

CADY: Nós vamos?

JANIS: Regina George é uma ditadora cruel. Como se derruba um ditador? Tirando os seus recursos. Regina não seria nada sem um namorado bonito, um corpo 
tecnicamente atraente e um grupo de seguidoras ignorantes e leais. Cady, para o plano dar certo, você vai ter que agir como se nada tivesse acontecido. Você pode fazer isso?

CADY: Eu posso fazer isso.

Por outro lado, Cady é exposta a diversas situações que nunca havia vivenciado antes, como gostar de alguém de verdade ou ter grupos de amigos. Portanto, a fim de se adaptar, molda seu comportamento de forma coerente com o que ela pensa que cada grupo que participa espera, agindo assim, em conformidade. Segundo Solomon (2016), conformidade é uma alteração de crenças ou ações como reação à pressão real ou imaginária do grupo.

Portanto, pode-se dizer que as mudanças ocorridas na vida de Cady, geraram o deslocamento e fragmentação de sua identidade, dando oportunidade para o surgimento de uma nova identidade, multifacetada e antagônica (Hall, 2005). Dessa forma, Cady passa a tomar decisões procurando adequar-se à nova realidade vivenciada. No entanto, ainda é possível perceber a forte influência que a cultura africana exerce sobre Cady. Algumas cenas salientam, pelo olhar da personagem, como seria se os conflitos velados fossem substituídos pela selvageria sincera das planícies africanas. Essa prática expressa o valor do contexto cultural em que a personagem estava inserida, bem como o significado de tudo aquilo que a circundava, como os animais, a savana, os bens pessoais trazidos de lá e as lembranças (Araujo \& Rocha, 2016).

Conforme expresso por Solomon (2016), os integrantes de um grupo apontam mais disposição para considerar escolhas mais arriscadas após discussões com o grupo do que quando tomam suas próprias decisões, sem discuti-las com ninguém. Segundo o autor, quanto mais pessoas estiverem envolvidas em uma decisão, menos responsável pelo resultado será o indivíduo. Portanto, Cady, Janis e Damian tomam decisões tendenciadas ao risco a fim de alcançar seus objetivos e, portanto, "solucionar o problema" (Peter \& Olson, 2009).

JANIS: Olha, não é porque eu a odeio. Só que seria divertido se você andasse com elas e ouvisse tudo que dizem.

CADY: Do que vamos falar?

JANIS: Produtos para cabelo.

DAMIAN: Ashton Kutcher.

\section{O Poder de informação}

0 filme mostra que a vida da personagem principal é transformada a partir da sequência 14, quando Regina George beija Aaron Samuels na festa de Halloween. A partir de então, o comportamento da protagonista Cady Heron para com Regina George, perpassa em influenciar com o intuito de prejudicar. De maneira pragmática, Cady se aproveita da vaidade de Regina, oferecendo-lhe coisas que possam ajudá-la a alcançar seus objetivos de estética. Mesmo que Regina não tenha certeza da veracidade das informações e produtos fornecidos por Cady, a mesma acredita, pois, pensa que Cady detém informações das quais ela desconhece.

Obcecada pela ideia de eliminar o "reinado" de Regina, Cady utiliza como base de poder o poder de informação de maneira racional, envolvendo o uso da lógica e barganha, consistindo no apelo ou tentativa de obter um raciocínio instrumental por parte do alvo (Somech \& Drach-Zahavy, 2002). Raven (1992) explica a influência originária da informação como uma mudança básica em elementos cognitivos do alvo, indicando a informação comunicada pelo agente como a base dessa mudança. Ainda segundo esse autor, o poder de informação ou persuasão está apoiado na informação ou no argumento lógico aplicado pelo agente influenciador.

Uma cena que mostra Cady exercendo seu poder de informação sobre Regina pode ser observada a seguir, quando Cady oferece à Regina barras nutritivas para engordar dizendo que servem para emagrecer:

CADY: São barras de nutrição que minha mãe usa para perder peso.

REGINA: Me dê isso aqui. Está tudo em sueco. 
CADY: É, acho que tem um ingrediente que ainda não é legal na América.

REGINA: Efedrina?

CADY: Não.

REGINA: Fenomina.

CADY: Não. Queima carboidratos. Ajuda a queimar os carboidratos.

Segundo os estudos de alguns autores como D’Rozario e Choudhury (2000), Park e Lessig (1977), Peter e Olson (2009) e Solomon (2016), sobre influência informacional, o indivíduo aceita a apreciação crítica, recomendação ou experiência de terceiros, em relação a um produto, serviço ou determinada marca, pelo fato de ele acreditar que aquela pessoa é detentora de determinado conhecimento sobre os mesmos, quer seja pela observação, uso ou contato anteriores.

Conforme enfatizam Somech e Drach-Zahavy (2002), o objetivo é ofertar ao alvo um curso de ação de acordo com a demanda do agente e que irá, presumivelmente, maximizar o valor esperado de algum resultado significativo para o alvo. Nesse contexto, Cady apresenta um background informacional que serve, subsequentemente, para aumentar sua influência baseada em informações, com o intuito de persuadir Regina a aceitar sugestões. Uma outra cena que ilustra bem o poder de informação de Cady, é quando Regina vai à uma loja experimentar um vestido para a festa de primavera e, no entanto, o vestido não cabe mais:

REGINA: Cady, tudo que tenho comido são essas barras. São uma droga!

CADY: Não, é assim que funciona. Esse peso é só água. Você incha, mas depois perde cinco quilos de uma vez só. Você queimou os carboidratos e está sobrevivendo de líquidos. Quando o líquido é eliminado, só sobra músculos. Está tudo escrito na embalagem.

REGINA: Você sabe ler sueco?

CADY: Na África todos entendem sueco.

De acordo com Peter e Olson (2009), os indivíduos tendem a ser mais influenciados pelos grupos de referência quando as informações recebidas são confiáveis e pertinentes ao problema em questão, e a fonte das informações é digna de credibilidade. Este tipo de influência, porém, não é imposta à Regina, ela só ocorre em detrimento de Regina acreditar que a informação recebida é compatível com a realidade em torno daquele produto, pois Cady, fonte da informação, possui confiabilidade. Um exemplo é quando Regina reclama das espinhas em seu rosto e Cady diz ter um creme para pele ótimo, Regina então passa a utilizar o creme sem saber que Cady havia dando-lhe creme para os pés.

Durante o desenrolar da narrativa, pode-se observar que Regina encontra dificuldade em tomar decisões quanto a sua alimentação, precisando de recomendações externas do grupo ou de Cady, que possui um discurso com informações potencialmente úteis. Uma vez conquistada a confiança e credibilidade de Regina, Cady passa a ter total autonomia para influenciar seu comportamento de consumo alimentício, podendo assim, colocar em prática o plano de eliminar o corpo tecnicamente atraente da rival.

REGINA: Manteiga é carboidrato?

CADY: Sim.

0 consumo alimentício de Regina é parte de seu estilo de vida, que é influenciado diretamente pelo contexto social em que está inserida. Conforme expresso por Giddens (2002), as pessoas estão em busca de sua própria segurança ontológica, ao mesmo modo em que as alterações e inconstância de suas próprias escolhas confrontadas com a de outros, pode gerar processos de diferenciação e exclusão. Um exemplo dessa diferenciação e exclusão de que fala o autor pode ser observado na sequência 26, quando Regina George é impedida de sentar na mesa das poderosas por infringir as regras de vestimenta: 
GRETCHEN: Regina, você está usando moletom. Hoje é segunda-feira.

REGINA: E daí?

KAREN: Isso é contra as regras, você não pode sentar com a gente.

REGINA: E daí? As regras não valem.

KAREN: Valiam quando eu usei colete!

REGINA: Porque aquele colete era horrível.

GRETCHEN: Não pode almoçar com a gente!

Conforme salientado por Raven (1990), há outros meios pelos quais as pessoas podem influenciar as outras, como por exemplo a manipulação ambiental, que consiste em o agente não influenciar o alvo diretamente, mas modificar a situação de tal forma que o alvo é levado a aceitar a influência. A manipulação ambiental de que fala o autor, pode ser observada a partir das atitudes de Cady para com Gretchen, pois a personagem articula para que Gretchen acredite que Regina não a considera mais como amiga. Uma cena que representa o início da manipulação ambiental feita por Cady pode ser observada abaixo, quando Cady envia bengalas de açúcar para si mesma e para Karen fingindo ser Regina George:

GRETCHEN: Quem a mandou?

CADY: “Obrigada por ser uma amiga tão legal. Com amor, Regina”. Que gentil.

\section{CONCLUSÕES}

Este artigo teve por objetivo investigar como a influência dos grupos de referência e o poder social que estes exercem, influenciam nas práticas de consumo e na adequação da identidade individual das pessoas. A partir da análise de determinados personagens que compõem a história do filme Meninas Malvadas (Mean Girls, 2004), propõe-se algumas considerações que retomam a indagação inicial: de que maneira o texto cultural estudado ajuda a compreender a influência e o poder social dos grupos de referência no comportamento de consumo dos indivíduos?

A análise do filme evidencia, por meio do poder social, um sistema que distingue as táticas de influência dos personagens, o que permitiu gerar quatro categorias, são elas: o poder coercitivo, o poder de recompensa, o poder de legítima reciprocidade e o poder de informação. Foi interessante perceber que as táticas de influência se modificam de acordo com a percepção que o agente espera que o alvo influenciado tenha, estabelecendo bases de poder para disfarçar o poder social exercido sobre este último. Segundo French e Raven (1959) o poder coercitivo refere-se ao poder que uma determinada pessoa tem em estabelecer punições sobre outrem; o poder de recompensa baseia-se ao controle de um estabelecer prêmios ou recompensas sobre o outro; o poder de legítima reciprocidade baseia-se no reconhecimento de uma pessoa de que a outra tem o poder legal, concludente, de influenciá-la e que ela tem por obrigação aceitar esta influência; já o poder de informação diz respeito ao fato de uma pessoa acreditar que a outra domina determinado assunto e que, por isto, não deve questioná-la.

Curiosamente, diferentes fenômenos foram observados, como, por exemplo, os sentimentos antagônicos de Cady Heron por Regina George, pois, ao mesmo modo que Cady tem como motivação o intuito de prejudicar e se vingar de Regina, deseja também que o alvo em questão goste dela. Esse desejo, porém, está associado à tática branda de influenciação utilizada por Regina sobre Cady, fazendo com que esta seja influenciada sem que haja resistência. Outro exemplo interessante foi observado com Gretchen, que ao longo do filme foi a personagem que mais sofreu com a interação de influência interpessoal dos demais personagens, apresentada inicialmente como uma plastic que, no meio da narrativa, com a dissociação do grupo, passa a seguir a personagem Cady Heron e, no final, é apresentada como uma "asiática legal", evidenciando assim, sua necessidade de sempre ter uma pessoa ou grupo como referencial para espelhar suas atividades e práticas de consumo.

Tomando como base as contribuições de Jenkins (2005) aos estudos da identidade, um dos achados desse trabalho foi a mudança provocada na identidade de Cady Heron, a partir das características absorvidas da sociedade em que a personagem está inserida. Apesar de a influência 
cultural africana ser bastante marcante nesta personagem, constatada pelo significado atribuído aos objetos e lembranças trazidos de lá, pode-se perceber que, ao decorrer do filme, essa influência vai se extinguindo, comprovando que a identidade é um processo contínuo de "estar" e "se tornar", dando oportunidade para o surgimento de novas identidades.

Os achados dessa pesquisa indicam que os grupos de referência influenciam fortemente não somente nas práticas de consumo dos indivíduos, mas, também, na conduta, nos pensamentos e padrões de comportamento. A análise da personagem Cady Heron se revela capaz de fomentar essa assertiva, pois a mesma passa a ter preocupações com sua estética, vestimenta e posição social após interação com o grupo das plastics. Ainda que tenham regras de vestimenta impostas pelo grupo, com o desenrolar da narrativa, é possível perceber que a personagem passa, de maneira interdependente, a ter a mesma aspiração de consumo do grupo à qual pertence.

É importante observar ainda que estudar o comportamento do consumidor reside em analisar indivíduos e grupos nas suas especificidades e a forma como selecionam, adquirem e consomem produtos e serviços a fim de satisfazer às suas necessidades. Porém, algumas variáveis podem influenciar esse comportamento de consumo, como por exemplo o fator social, representado no texto cultural em análise pela personagem Regina George que, pela busca incessante do corpo perfeito decide mudar suas práticas alimentares. Contudo, a personagem passa a ser influenciada pelo poder informacional de Cady Heron, se alimentando então de acordo com as diretrizes de Cady, sempre a perguntando informações sobre os alimentos que pretende ingerir.

Um outro achado que merece ser destacado é a importância da cultura no comportamento do consumidor, pois a pesquisa permitiu refletir sobre a influência do consumo para a construção da identidade e, nesse sentido, a influência do grupo de referência. 0 progresso de estudos fundamentados em abordagens metodológicas, ainda pouco desenvolvidas no campo de grupos de referência, pode enriquecer o entendimento do fenômeno ao indicar novos parâmetros de pesquisa na área. Ainda que a análise fílmica constitua um árduo exercício metodológico devido à dificuldade de se investigar imagens em movimento do que é exibido na tela, esse tipo de análise pode instituir uma alternativa de compreensão de conceitos ilustrativos da realidade dos grupos de referência e do comportamento do consumidor.

De outro lado, a pesquisa também contribui para o mercado pois oferece uma visão oportuna sobre o comportamento de consumo e segregação dos indivíduos e o efeito que a popularidade social exerce sobre as pessoas. Por meio da análise de determinados personagens que compõem a história do filme, surge a possibilidade de se perceber como os grupos de referência moldam as preferências daqueles que participam do grupo, seja pelo desejo de agradar, de passar a ideia de pertencimento ou de ser aceito pelo grupo e socialmente, sendo útil, portanto, para ajudar os profissionais de marketing a entender como esses grupos se organizam e como influenciam os demais.

Por meio da dimensão humana do grupo de referência, busca-se, portanto, acessar os códigos que revestem seu agir, indo além dos discursos que trazem o consumo como uma prática individualizada. Por isso, recomenda-se que temas diversos na área de comportamento do consumidor sejam analisados por meio de filmes, tais como as redes de relacionamento, a segregação dos indivíduos, construção da identidade, a identidade coletiva e o poder social nos grupos de referência, cuja relação não tende a ser contemplada nos estudos do campo.

\section{Referências}

Ahuvia, A. C. (2005). Beyond the extended self: loved objects and consumers' identity narratives. Journal of Consumer Research, 32(1), 171-184.

Andrew, J. D. (2002). As principais teorias do cinema: uma introdução. Rio de Janeiro: Jorge Zahar.

Araujo, F. F., \& Rocha, A. (2019). The redefining of later life through leisure: music and dance groups in Brazil. Leisure Studies, 38(5), 712-727.

Araujo, F. F., Turano, L. M., \& Vieira, F. C. (2019). Subculturas Religiosas de Consumo: Um estudo etnográfico de jovens católicos nas práticas dos Exercícios Espirituais. Consumer Behavior Review, 3(2), 99-119. 
Araujo, F. F., \& Rocha, A. (2016). Significados Atribuídos ao Lazer na Terceira Idade: Observação Participante em Encontros Musicais. Podium: Sport, Leisure and Tourism Review, 5(2), 38-55.

Araujo, F. F., \& Chauvel, M. A. (2014). Filmes franceses no mercado brasileiro - refletindo sobre as estratégias promocionais de uma distribuidora independente: um caso de ensino. Revista de Economia e Administração, 13(1), 115-142.

Araujo, F. F., \& Chauvel, M. A. (2012). Marketing de Cinema Francês no Brasil: Um estudo exploratório sobre as estratégias de promoção para o lançamento de filmes no mercado brasileiro. FACEF Pesquisa: Desenvolvimento e Gestão, 15(3), 298-315.

Barbosa, L., \& Campbell, C. (2006). Cultura, consumo e identidade. FGV Editora.

Barry, B., \& Shapiro, D. L. (1992). Influence tactics in combination: the interactive effects of soft versus hard tactics and rational exchange. Journal of Applied Social Psychology, 22, 1429-1441.

Bastos, A. F. V., Costa, F. J., \& Vasconcelos, M. M. (2017). Consumo de Bebidas Alcoólicas por Jovens: Implicações para o Marketing Social. Revista Brasileira de Marketing, 16(4), 469-486.

Bauman, Z. (2005). Work, consumerism and the new poor. Berkshire: Open University Press.

Bearden, W. O., Netemeyer, R. G., \& Teel, J. E. (1989). Measurement of Consumer Susceptibility to Interpersonal Influence. Journal of Consumer Research, 15, 473-481.

Bearden, W.O., \& Etzel, M. (1982). Reference Group Influence on Product and Brand Purchase Decisions, Journal of Consumer Research, 9, 183-194.

Belk, R. (1988). Possessions and extended self. The Journal of Consumer Research, 15 (2).

Belk, R. (1989). Extended self and extending paradigmatic perspective. Journal of Consumer Research, $16,129-132$.

Birdwhistell, R. L. (1970). Kinesic in context: essays on body-motion communication. Harmondsworth: Penguim.

Blackwell, R. D., Miniard, P. W., \& Engel, J. F. (2005). Comportamento do Consumidor. São Paulo: Pioneira Thomson Learning.

Breheny, M., \& Stephens, C. (2017). Spending time: the discursive construction of leisure in later life. Annals of Leisure Research, 20(1), 39-54.

Cabrera, J. (2006). O cinema pensa: uma introdução à filosofia através dos filmes. Rio de Janeiro: Rocco.

Camelo, C. O., Thomé, K. M., \& Junqueira, A. M. R. (2018). Café e Valores de Consumo dos Brasileiros. Revista Brasileira de Marketing, 17(2), 220-236.

Campbell, C. (1991). The new wave of research in the humanities and social sciences. Journal of Social Behavior and Personality, 6 (6), 57-74.

Cordeiro, R. I. de N. (1996). Informação cinematográfica e textual: da geração à interpretação e representação de imagem e texto. Ciência da Informação, 25(3).

Coutinho, I. (2005) Leitura e análise da imagem. In: Duarte, J., \& Barros, A. Métodos e técnicas de pesquisa em comunicação. São Paulo: Atlas.

Dias, R. (2009). Fundamentos de sociologia geral. Campinas, SP: Editora Alínea.

Dodson, K. (1996). Peak experiences and mountain biking: Incorporating the bike into the extended self. Advances in Consumer Research, 23(1), 317-322.

D’Rozario, D., \& Choudhury, P. K. (2000). Effect of Assimilation on Consumer Susceptibility to Interpersonal Influence. Journal of Consumer Marketing, 17(4), 290-307.

Engel, J., Blackwell, R., \& Miniard, P. (2005). Comportamento do Consumidor. Nona Edição, Thomson, São Paulo.

Farias, M. L., Sousa Júnior, J. H., Silva, B. G. F., \& Alcoforado, D. G. (2019). Compreendendo o Domínio "Projetos de Identidade do Consumidor": Revisão de literatura considerando a produção científica brasileira. Consumer Behavior Review, 3(2), 85-98.

French Jr., J. R. P., \& Raven, B. H. (1959). The Bases of Social Power, In: cartwright, D. ed. Studies in Social Power. Ann Arbor: University of Michigan Press, p. 150-167.

Geertz, C.A. (1973). The interpretation of cultures. New York: Basic Books.

Giddens, A. (2002). Modernidade e identidade. Rio de Janeiro: Jorge Zahar Ed.

Hall, S. (2005). A identidade cultural na pós-modernidade. 10. ed. Rio de Janeiro: Guaracira Lopes Louro. 
Hirschman, E., Scott, L., \& Wells, W. B. (1998). A Model of Product Discourse: Linking Consumer Practice to Cultural Texts. Journal of Advertising, 27(1).

Hirschman, E., \& Stern, B. B. (1994). Women as Commodities: Prostitution as Depicted in the Blue Angel, Pretty Baby and Pretty Woman. Advances in Consumer Research, 21.

Holbrook, M. B. (1999). Popular Appeal versus Expert Judgments of Motion Pictures. Journal of Consumer Research, 26 (1), 144-155.

Holt, D. B. (2002). Why do brands cause trouble? A dialectical theory of consumer culture and branding. Journal of Consumer Research, 29, 70-90.

Jenkins, R. (2005). Social Identity. 3a ed. London: Routledge.

Kidder, L., \& Judge, C. (1986). Research methods in social relations. New York: CBS.

Kipnis, D., \& Schmidt, S. (1985). The language of persuasion. Psychology Today, 40-46, Apr.

Kleine III, R. E., \& Kernan, J. B. (1988). Measuring the meaning of consumption objects: anempirical investigation. Advances in Consumer Research, 15, 498-504.

Lima, E. B., Costa, C. S. R., \& Félix, G. R. (2019). Emoções Culpa e Orgulho e Sua Influência na Intenção de Compra de Produtos Verdes. Consumer Behavior Review, 3(2), 70-84.

Loizos, P. (2002). Vídeo, filme e fotografias como documentos de pesquisa. In: Bauer, M. W. e Gaskell, G. (Orgs.). Pesquisa qualitativa com texto, imagem e som: um manual prático. Petrópolis: Editora Vozes, 137-155.

MacInnis, D., \& Folkes, V. (2010). The disciplinary status of consumer behavior: a sociology of science perspective on key controversies. Journal of Consumer Research, 36.

McCracken, G. (1988). Culture and Consumption: New approaches to the symbolic character of consumer goods and activities. Bloomington: Indiana Press University.

Mehta, R., \& Belk, R. (1991). Artifacts, identity and transition: favorite possessions of Indians and Indian immigrants to the United States, Journal of Consumer Research, 17(4), 398-441.

Minayo, M. C. (1992). O desafio do conhecimento: pesquisa qualitativa em saúde. 7. ed. São Paulo: Hucitec.

Park, G. W., \& Lessig, V. P. (1977). Students and Housewives: differences in susceptibility in reference group influence. Journal of Consumer Research, 4(1).

Passarelli, C. A. (2004). Imagens em diálogo: filmes que marcaram nossas vidas. In: Spink, M. J. (Org.). Práticas discursivas e produção de sentidos no cotidiano. São Paulo: Cortez.

Peter, J. P., \& Olson, J. C. (2009). Comportamento do Consumidor e Estratégia de Marketing. 8. ed. - São Paulo: McGraw-Hill.

Raven, B. H. (1990). Political applications of the psychology of interpersonal influence and social power. Political Psychology, 11, 493-520.

Raven, B. H. (1992). A power/interaction model of interpersonal influence: French and Raven thirty years later. Journal of Social Behavior and Personality, 7, 217-244.

Rodrigues, A., Assmar, E. M. L., \& Jablonski, B. (2003). Psicologia social. 22.ed. Petrópolis, Rio de Janeiro: Vozes.

Rose, D. (2002). Análise de imagens em movimento. In: BAUER, M. W.; GASKELL, G. Pesquisa qualitativa em texto, imagem e som: um manual prático. Petrópolis: Vozes.

Sahlins, M. (1976). Cultura e razão prática. Rio de Janeiro: Jorge Zahar Editora.

Sanders, C. (1990). The animal 'other': Self definition, social identity and companion animals. Advances in Consumer Research, 17(1), 662-668.

Scott, D., \& Harmon, J. (2016). Extended leisure experiences: A sociological conceptualization. Leisure Sciences, 38(5), 482-488.

Sheth, J. N., Mittal, B., \& Newman, B. I. (2001). Comportamento do Cliente: indo além do comportamento do consumidor. Tradução de Lenita M. R. Esteves. Revisão técnica: Rubens da Costa Santos. São Paulo: Atlas.

Silverman, D. (1993). Interpreting Qualitative Data: methods for analysing talk, text and interaction. Londres: Heinemann.

Slater, D. (2002). Cultura, consumo e modernidade. São Paulo: Nobel.

Smith, E. R., \& Henry, S. (1996). An in-group becomes part of the self: Response time evidence. Personality and Social Psychology Bulletin, 22, 635-642. 
Solomon, M. R. (2016). Comportamento do consumidor: Comprando, possuindo e sendo. 11 $\underline{\text { a }}$ ed. Porto Alegre: Bookman.

Somech, A., \& Drach-Zahavy, A. (2002). Relative power and influence strategy: the effects on agent/target organizational power on superiors' choices of influence strategies. Journal of Organizational Behavior, 23(2), 167-179, Mar.

Suarez, M. C., Motta, P. C., \& Barros, C. (2009). Consumo e castigo: um retrato das relações de consumo no seriado A Diarista. In: XXXIII EnANPAD - Encontro Nacional da Associação Nacional dos Programas de Pós-Graduação em Administração. Anais... São Paulo: ANPAD.

Thompson, C. J. (1997). Interpreting Consumers: A hermeneutical framework for deriving marketing insights from the texts of consumers' consumption stories. Journal of Marketing Research, 34, 438-455.

Tian, K., \& Belk, R. (2005). Extended self and possessions in the workplace. Journal of Consumer Research, 32, (2), 297-310.

Vouga, A. (2017). Influências contraculturais no consume colaborativo: Insights no contexto do Couchsurfing.com. Consumer Behavior Review, 1(2), 73-81.

Wearing, M. (1993). Professional discourse and sensational journalism: media constructions of violent insanity. Australian Journal of Communication, 20(1), 84-97.

Wood Jr., T. (1997). Terra em transe: liderança em Eldorado. In: Motta, F. C. P., \& Caldas, M. P. (Org.). Cultura organizacional e cultura brasileira. São Paulo: Atlas. 